\title{
Do mirante, um facho de luz: trajetória biográfica de um militante de esquerda
}

\author{
From the Lookout, a Beam of Light: the \\ Biographical Trajectory of a Left-Wing Activist
}

Frank Antonio Mezzomo*

SCHMIDT, Benito Bisso. Flavio Koutzii: biografia de um militante revolucionário. De 1943 a 1984. Porto Alegre: Libretos, 2017.

"Vocês sabem, o sonho não acabou", escreveu Flavio Koutzii a seus amigos em 1979, em ocasião de sua rápida passagem por São Paulo com destino à França, logo depois de conquistar a liberdade da prisão argentina, onde sobreviveu por quase cinco anos. A frase poderia ser fortuita se não trouxesse uma densa carga simbólica: a militância política iniciada em Porto Alegre (RS), nos anos 1960; o exílio em 1970, provocado pelo acirramento da ditadura civil-militar brasileira; e os anos de perseguição, tortura e prisão na Argentina, impingindo no sujeito sequelas físicas, morais e psicológicas. Tais situações, ao que parece, não demoveram de Koutzii a utopia revolucionária, construída e inspirada nos princípios do socialismo trotskista.

Um indicativo de que o sonho não acabara, não obstante as controvérsias vividas na clandestinidade e o sofrimento passado nos porões da ditadura porque seu retorno ao Brasil, em 1984, depois de um período na França, implicou na construção de uma trajetória política intensa (ele se torna vereador, deputado estadual por quatro mandatos e Chefe da Casa Civil do Governo no Rio Grande do Sul; sempre pelo Partido dos Trabalhadores, o qual também ajudou a conceber ainda no final da década anterior). Se o envolvimento político-partidário se estende até 2007, sua militância na defesa de pautas públicas é uma constante. Afinal, desde os anos 1960 até a atualidade, tornou-se conhecido não apenas pelo engajamento social, mas pela publicação e organização de livros, cadernos e materiais de divulgação, entrevistas e colunas assinadas para diversos periódicos nacionais, quando, em geral, dissertava sobre

\footnotetext{
* Universidade Estadual do Paraná (UNESPAR), Campo Mourão, PR, Brasil. frankmezzomo@gmail. com <https://orcid.org/0000-0003-0968-6777>
} 
política e economia nacional e latino-americana, assim como tecia reflexões sobre teóricos e clássicos das Ciências Sociais (Koutzii, 1984; 2017; 2020). Sua trajetória biográfica pode ser compreendida como a de um intelectual de fina racionalidade, porque, além de transmitir ideias, promoveu debates, levantou problemas e elaborou programas intervenientes, ao atuar como mediador cultural e ator político em diversos espaços de sociabilidade (Bobbio, 1997; Sirinelli, 2003).

Flavio Koutzii é o personagem central do livro do historiador Benito Bisso Schmidt que propôs compreender a trajetória de vida desse militante revolucionário, pinçando elementos da sua família, mesmo antes de seu nascimento, a fim de entender o clima cultural de Porto Alegre dos anos trinta e quarenta até 1984, quando o biografado retorna ao Brasil, após período passado na Europa. Benito apresenta encruzilhadas, caminhos interrompidos e projetos realizados de um personagem enigmático de nossa história recente, convidando o leitor a compreender a constituição do Brasil a partir da potência da biografia, não se engambelando no microcosmo e no voyeurismo do sujeito, tampouco se deixando engolir pelas metanarrativas e macrovisões de matriz galileana e estruturalista (Loriga, 2011; Chartier, 1994). A partir da metáfora da visão aérea e do nadador de Norbert Elias (1994), o biógrafo coloca como desafio de pesquisa alterar e articular as visões de cima e de dentro, pulando, sem perder o equilíbrio, do avião ao rio e vice-versa, a fim de problematizar o campo de possibilidades em que Flavio Koutzii constrói sua historicidade. Entendo que tal empreendimento historiográfico é bem sucedido, afinal, o personagem aparece como figura de proa em toda a narrativa do livro, como, aliás, se espera de uma biografia, mesclado e complexificado com os movimentos da história que, em tese, independem da vontade do sujeito, mas também são ressignificados por ele.

O livro apresenta razões para surpreender o leitor, do especialista àqueles que se interessa por biografias, afinal, parafraseando Arendt (2008) e Borges (2008), é resultado de um trabalho de fôlego, detalhadamente documentado, densamente anotado e generosamente articulado com citações que contam sobre o personagem e a sociedade em questão, mais intensamente que inúmeros livros de história. A obra surge na esteira de um movimento historiográfico de "retorno" e valorização do gênero biográfico (Dosse, 2015; Avelar; Schmidt, 2018), ao dialogar com ele e contribuir teórica e metodologicamente. A despeito da narrativa problematizadora sobre o personagem Flavio Koutzii - a partir do qual se conhece um capítulo da esquerda brasileira e suas articulações latino-americanas e europeias -, ponderarei sobre dois conjuntos de elementos 
que o livro permite debater: o primeiro, em torno da composição da obra; e o segundo, acerca da experiência do autor, que, ao tratar do biografado, traz candente e de forma transparente seu lugar de fala, suas opções e preferências teóricas e políticas. Vamos a eles.

Em relação à composição do livro, uma nota inicial: por se tratar desse tipo de material e não de um artigo, que é objetivo e mais pontual, é possível dissertar sobre os resultados de pesquisa com mais vagar, o que torna a investigação sólida empírica e metodologicamente, além de permitir uma densidade teórica que requer articulação e refinamento argumentativo. É isso que Benito apresenta ao longo de mais de quinhentas páginas de uma pesquisa que desenvolveu em quase dez anos. É fácil identificar, na organização do livro, desde os aspectos gráficos e artísticos até a definição das partes em que é apresentado o conteúdo, o cuidado e as escolhas feitas pelo autor, o que demonstra, além do zelo pessoal, uma preocupação com o leitor, interlocutor da pesquisa. Além disso, essa perspectiva chama a atenção para uma dinâmica em curso, ainda tímida na academia, que é acionar outros estilos, saberes, linguagens a fim de incluir públicos e audiências diversas, não só como consumidores de histórias, mas como interlocutores e parceiros nos empreendimentos de produção de saberes e práticas (Cauvin, 2019; Fagundes, 2019). Ao tratar da história de Flavio Koutzii e com ele dialogar, Benito remete à noção de autoridade compartilhada, entendendo que o texto é moldado a partir de trocas e negociações (in)conscientes (Schmidt, 2017).

Nessa dinâmica é construída a narrativa do livro, trazendo diversas fontes iconográficas, tais como recortes de jornal, fotos, cópias de passaportes, documentos estudantis, boletim escolar, fichários e relatórios da polícia política do Brasil e da Argentina, cópia de lista de livros lidos na prisão e de abaixo-assinados solicitando a liberdade de Flavio, constando assinaturas de relevantes intelectuais europeus - como Simone de Beauvoir, Michel Foucault, Jacques Rancière, Edgard Morin, Nicos Poulantzas -, e diversos impressos de época, como panfletos, revistas, capas e fragmentos de livros mimeografados.

A articulação das fontes imagéticas com a narrativa da pesquisa permite que o leitor visualize a documentação de época, dimensione as interpretações e conclusões do autor, além de tornar a leitura mais fluída e intuitiva, embora, em certos momentos, o texto seja marcado por longos excertos de entrevistas. A quantidade e a disposição das imagens são adequadamente distribuídas e integradas à discussão, com uma nota em especial para algumas fotos e imagens de momentos marcantes da vida do biografado, tais como a de sua saída da prisão na Argentina, a da reconstrução pessoal com sua companheira na 
França, a de sua eleição em 1988, em Porto Alegre, a de encontros com personalidades políticas e intelectuais do Brasil e do estrangeiro. Há ainda, ao final do livro, uma sequência de fotos com seu biógrafo, o que coroa o entendimento de como é trabalhar em história pública, para públicos mais amplos, quando a autoria e a autoridade são divididas e compartilhadas, como Benito mencionou noutros momentos (Zalla; Rufatto, 2016).

Ainda no que concerne à composição, o livro é constituído por cinco capítulos que cobrem parte da vida em família e a infância na Porto Alegre dos anos 40 a 50; a potência dos anos 60, em que explora as vivências e a militância política na Universidade, os conflitos e reveses dos projetos pessoais e políticos decorridos do golpe militar e a fuga do Brasil em 1970. Nos terceiro e quarto capítulos, o autor mergulha nas experiências vividas por Koutzii no Chile e na Argentina, onde as sociabilidades são construídas na clandestinidade, nos porões das prisões e na campanha pela anistia política ocorrida no Brasil em 1979. Por fim, o quinto capítulo trata da sua passagem pela França (1979-1984), período doloroso de reconstrução pessoal, afinal, ele tratava de se recuperar das marcas da tortura, do medo e da culpa, dos "pedaços de morte no coração" provocados pela política terrorista de Estado argentino - como, aliás, já apontado pela literatura (Canelo, 2014; Fico, 2013; Capelato, 2006; Novaro; Palermo, 2003), a qual Benito faz questão de ratificar, com base na documentação compilada em sua investigação.

Duas contribuições completam o livro: uma de Guilherme Cassel, em que discorre sobre pautas polêmicas defendidas pelo biografado quando deputado estadual, Chefe da Casa Civil e Assessor Especial do Governo do Rio Grande do Sul; e o posfácio do próprio sujeito do livro, Flavio Koutzii, que fala da experiência de se pensar a partir da própria biografia e vaticina sua prospecção utópica, tão marcada ao longo do livro, quando diz da "longa marcha para reconstruir o país, recuperar direitos, reflorestar as palavras, reler os poemas, ouvir nossas canções" (Koutzii, 2017, p. 525). Podemos afirmar que o conteúdo, embora extenso, é adequadamente distribuído, contando, cada capítulo, com a apresentação de seus objetivos e propósitos. Já o final de cada capítulo apresenta sínteses e conclusões, deixando evidente ao leitor o percurso adotado pela obra.

O segundo conjunto de elementos que o livro permite cotejar refere-se à experiência do autor, que tece, como um artesão, os fios que compõem a pesquisa resenhada. A obra expressa conhecimento de quem transita no gênero biográfico e, ao lado de outras produções bibliográficas, marca sua contribuição para a escrita da história e o seu lugar entre os historiadores brasileiros. $\mathrm{O}$ 
investimento intelectual do autor encontra legitimidade na trajetória construída ao longo de sua carreira. A biografia está no seu horizonte desde a década de 1990, quando começou a escrever sobre o tema, aprofundando-o, posteriormente, com suas pesquisas de mestrado e doutorado, também publicadas em formato de livro. Em particular, a investigação sobre Flavio Koutzii, desenvolvida num longo período, foi articulada com pesquisas mais breves que envolveram estudantes de graduação, vinculadas a programas institucionais de iniciação científica. Temos, assim, um corpus documental robusto e diverso, cobrindo diferentes experiências em que o biografado foi envolvido pelas circunstâncias históricas no Brasil, no Chile, na Argentina e na França. A gestão de uma pesquisa dessa magnitude requer disciplina, organização, planejamento pessoal e logístico, a fim de não sucumbir à burocracia que grassa nossa prática investigativa e à sedução pela publicação rápida e, às vezes, rasa, em artigos e capítulos, que fragilizaria a consistência do resultado final.

Assim, vemos no texto um historiador experiente que faz uma adequada apropriação conceitual e metodológica, superando os usos das tradicionais citações bibliográficas e, talvez, mais prejudiciais para o conhecimento, das tentativas de enquadramento da realidade aos referenciais teóricos construídos noutros tempos/espaços e, portanto, distantes das contingências socioculturais que tangenciam o "objeto" da investigação. Identificamos o acionamento diversificado da literatura - de abordagem interdisciplinar e recorrendo a noções como geração, identidade, memória, poder, campo de possibilidades -, antropofagicamente assimilado e instrumentalizado para compreender o indivíduo. O historiador demonstra, com a trajetória de Koutzii, que nenhum sistema normativo é suficientemente estruturado para eliminar a possibilidade de escolha, manipulação, interpretação ou subversão de leis e costumes (Velho, 2003; Levi, 2006). Embora seja possível ter-se a sensação de que, às vezes, o Estado é narrado quase como um ente metafísico - sem nomes e personagens, sujeitos que negociam, interpretam e respondem pelo Estado -, é correto mencionar que seu biografado é inserido no tempo e no espaço, onde é envolvido pelos golpes militares que se ampliaram na América do Sul e pelas conexões nacionais, latinas e intercontinentais estabelecidas pela esquerda.

Outro aspecto refere-se aos desafios epistemológicos e éticos da pesquisa em História, que passa pela interrogação de qual deve ser o papel do historiador e de como abordar memórias tão dolorosamente vivenciadas pelos sujeitos, marcadas pelas sevícias físicas e psicológicas decorrentes da política terrorista de Estado. Além dos limites da linguagem - como narrar o indizível e o inenarrável na sua complexidade -, Benito entende que grafar uma vida é ato moral- 
mente carregado que deixa marcas no biógrafo, no biografado e naqueles que consomem as biografias (Schmidt, 2014). Não se trata de absorver, analisar e transcrever uma vida, senão de compartilhar e intuir junto com as histórias de vida desses sujeitos. O autor defende que a "escrita de uma vida" não deve ser feita a qualquer custo, como se estivesse desnudando o personagem e, nele, provocando prejuízos simbólicos e materiais, afinal, os princípios éticos devem balizar a investigação e nortear a pesquisa, na tentativa de se compreender a sociedade e os seus mecanismos de normatização e formação de sociabilidades. Reconhece, com isso, os dilemas da análise histórica e da necessidade de aceitar que os instrumentos conceituais e metodológicos são insuficientes ou incompletos para explicar determinadas experiências históricas.

Enfim, Benito produz um livro escudado em sólida pesquisa de campo, com análises contundentes, que se materializa em um texto importante para os que apreciam biografias e manifestam interesses pela história do Brasil contemporâneo. Sua postura e arguição asseguram a relevância do gênero biográfico para a pesquisa e o ensino da história, assim como compartilham um projeto também comum a Flavio Koutzii: o de que outro mundo é possível, mesmo que controverso. Do mirante, um facho de luz em uma sociedade obscurecida por práticas não civilizatórias.

\section{REFERÊNCIAS}

AVELAR, Alexandre de Sá; SCHMIDT, Benito Bisso (Orgs.). O que pode a biografia. São Paulo: Letra e Voz, 2018.

ARENDT, Hannah. Homens em tempos sombrios. Tradução de Denise Bottmann. São Paulo: Companhia das Letras, 2008.

BOBBIO, Norberto. Os intelectuais e o poder: dúvidas e opções dos homens de cultura na sociedade contemporânea. São Paulo: Editora Unesp, 1997.

BORGES, Vavy Pacheco. Grandezas e misérias da biografia. PINSKY, Carla Bassanezi (Org.). Fontes históricas. 2 Ed. São Paulo: Contexto, 2008. pp. 203-233.

CANELO, Paula. Represión, consenso y “diálogo político". El Ministerio del Interior durante la última dictadura militar Argentina. Política/ Revista de Ciência Política, v. 52, n. 2, pp. 219-241, 2014.

CAPELATO, Maria Helena. Memória da ditadura militar Argentina: um desafio para a História. Clio - Revista de Pesquisa Histórica, v. 24, n. 1, pp. 61-81, 2006.

CAUVIN, Thomas. A ascensão da História Pública: uma perspectiva internacional. Revista NUPEM, v. 11, n. 23, pp. 8-28, 2019. 
CHARTIER, Roger. A história hoje: dúvidas, desafios, propostas. Estudos Históricos, v. 7, n. 13, pp. 100-113, 1994.

DOSSE, François. O desafio biográfico: escrever uma vida. Tradução de Gilson César Cardoso de Souza. 2 Ed. São Paulo: Edusp, 2015.

ELIAS, Norbert. A sociedade dos indivíduos. Rio de Janeiro: Zahar, 1994.

FAGUNDES, Bruno Flávio Lontra. História Pública brasileira e internacional: seu desenvolvimento no tempo, possíveis consensos e dissensos. Revista NUPEM, v. 11, n. 23, pp. 29-47, 2019.

FICO, Carlos. Violência, trauma e frustração no Brasil e na Argentina: o papel do historiador. Topoi, v. 14, n. 27, pp. 239-261, 2013.

KOUTZII, Flavio. Sonhos recomeçam neste instante em que os julgamos mais ausentes. 7 fev. 2020. Disponível em: https://www.sul21.com.br/opiniaopublica/2020/02/ sonhos-recomecam-neste-instante-em-que-os-julgamos-mais-ausentes-por-flavio-koutzii/. Acesso em: 14 mar. 2021.

KOUTZII, Flavio. Sou um deles e todos eles sou eu. In: SCHMIDT, Benito Bisso. Flavio Koutzii: biografia de um militante revolucionário. De 1943 a 1984. Porto Alegre: Libretos, 2017. pp. 523-525.

KOUTZII, Flavio. Pedaços de morte no coração. Porto Alegre: L\&PM, 1984.

LEVI, Giovanni. Usos da biografia. In: AMADO, Janaína; FERREIRA, Marieta de Moraes (Orgs.). Usos \& abusos da história oral. 8 Ed. Rio de Janeiro: Editora FGV, 2006. pp. 167-182.

LORIGA, Sabina. O pequeno $x$ : da biografia à história. Tradução de Fernando Scheibe. Belo Horizonte: Autêntica Editora, 2011.

NOVARO, Marcos; PALERMO, Vicente. La dictadura militar (1976-1983): del golpe de estado a la restauración de la democracia. Buenos Aires: Paidós, 2003.

SCHMIDT, Benito Bisso. Flavio Koutzii: biografia de um militante revolucionário. De 1943 a 1984. Porto Alegre: Libretos, 2017.

SCHMIDT, Benito Bisso. Quando o historiador espia pelo buraco da fechadura: biografia e ética. História (São Paulo), v. 33, n. 1, pp. 124-144, 2014.

SIRINELLI, Jean-François. Os intelectuais. In: RÉMOND, René (Org.). Por uma história política. 2 Ed. Rio de Janeiro: FGV, 2003. pp. 231-269.

VELHO, Gilberto. Projeto e metamorfose: antropologia das sociedades complexas. 3 Ed. Rio de Janeiro: Jorge Zahar, 2003.

ZALLA, Jocelito; RUFATTO, Katani Maria Monteiro. Sobre biografia e história: entrevista com Benito Bisso Schmidt. MÉTIS: história \& cultura, v. 15, n. 30, pp. 13-23, 2016.

Resenha submetida em 24 de março de 2021. Aprovada em 12 de julho de 2021. 